\title{
TESTING AN ASTRONOMICAL OBSERVING SITE IN ANTARCTICA
}

\author{
Pablo Recabarren and Juan Puerta \\ Observatorio Astronomico de Cordoba
}

During the winters of 1989 and 1990, the Observatorio Astronomico de Cordoba conducted observational site testing in the Antarctic. The search was carried out amongst the Argentinian stations to take advantage of existing logistic facilities. Belgrano II was chosen because it is the most southerly one, has the most stable climatological conditions, and is ground-based. The results are not very promising for astronomical work, but we have obtained important experience for this kind of task in the Antarctic.

The station has no building suitable for astronomical instruments, therefore the work was done in the open air, which made the measurements difficult. We measured seeing visually by means of the Danjon method, using a $20 \mathrm{~cm}$ reflecting telescope and observing several bright stars. Meteorological data was taken at the surface observation station which has been in use at Belgrano II since 1980. The real problem with the site is the climatic conditions rather than the seeing. When the weather is good we have good astronomical conditions but the weather is bad more than $50 \%$ of the time. Details are in Tables 1 and 2.

Table 1. Seeing

10 Jul to 8 Sep' 89 (60 days) 1 Apr to 25 Jul ‘90 (116 days)

$\%$ bad days

53

8.3

63

$\%$ with seeing $<1^{*}$

$\%$ with seeing $1^{\prime \prime}-1.5^{\circ}$

$\%$ with seeing $1.5^{*}-2^{*}$

$\%$ with seeing $2^{*}-2.5^{*}$

$\%$ with seeing $>2.5^{\circ}$

12

8.3

10

8.3

29

7

3

3

Table 2. Astronomically useful times (without wind, clouds and aurorae)

$\begin{array}{lcc}\text { month } & \text { Longest continuous period (hours) } & \text { Total period (hours) } \\ \text { April } & 15 & 135 \\ \text { May } & 39 & 139 \\ \text { June } & 78 & 131 \\ \text { July } & 114 & 341 \\ \text { August } & 126 & 312 \\ \text { May } \quad 1990 & 18 \text { on 5 occasions } & 309 \\ \text { June } & 75 & 135 \\ \text { July } & 45 \text { on 2 occasions } & 270 \\ \text { August } & 15 & 90 \\ \text { September } & \text { (Polar Spring) } & 45\end{array}$




\title{
Conclusions.
}

The site has proved to be the most adequate of the Argentinian Antarctic stations. There are some periods of very good observing conditions, as long as 126 hours, but it is difficult to develop a good observing program due to the uncertainty when these periods occur. During the good periods the turbulence and transparency of the sky are adequate for astronomical work, but auroral phenomena are very frequent. We think that the best place for astronomical observations should be far from the coast and the auroral zone. We will continue the work with a less subjective method than the one presented and with appropriate instruments.

Is Antarctica attractive for astronomical work? If there is some place with a stable climate, at high altitude, accessible at least each 2 months, with small snow accumulation and with a laminar regime of winds, we say YES! We think it is important to establish an astronomical observatory in the Antarctic.

\section{DAYTIME ASTRONOMICAL OBSERVING CONDITIONS AT SOUTH POLE}

\author{
J Harvey \\ National Solar Observatory, Tucson
}

The Sun has been observed at South Pole nearly every austral summer since 1979. This experience shows that the duration of uninterrupted observations is limited by clouds to runs of at best $\sim 150$ hours. Impressively high duty cycles can be achieved over longer periods. Sky clarity is often superb but even in cloudless conditions, ice crystal precipitation storms can be a problem. Daytime observations of the Sun and bright stars show that visible seeing quality is limited to about 2-3 arc seconds at altitudes of 15-20 degrees. Nearer the zenith, the seeing quality approaches 1 arc second in light wind. Seeing quality appears to vary with wind speed and direction and also diurnally with changing solar illumination of the surface ridges (sastrugi). Seeing is degraded by turbulence in the exceptionally large temperature gradient in the first few hundred meters above the surface. There are suggestions that both daytime and, perhaps more so, nighttime cloudiness increased over the last decade. This may be related to increasing amounts of $\mathrm{CO}_{2}, \mathrm{CH}_{4}$ and CFCs in the polar atmosphere. 